\title{
INVERSE MODEL USING LAND AND PROPERTY SUB-SYSTEMS FOR PLANNING FUTURE CITIES: A GENERAL FRAMEWORK
}

\author{
Ricardo Crespo ${ }^{a}$, Abbas Rajabifard ${ }^{b}$ \\ ${ }^{a}$ Universidad de Santiago de Chile, Santiago, Chile, \\ ${ }^{b}$ University of Melbourne, Melbourne, Australia
}

\section{Keywords:}

inverse model;

land and property

system;

urban complexity

\begin{abstract}
This paper suggests the use of the inverse model coupled with land and property systems to support urban decision-making. The inverse model is to be used for planning decisions today to achieve the desired tomorrow. This approach has been used previously in urban planning with a property system. The use of a property system alone is insufficient in dealing with the complexity of urban systems. Complex systems are made up of sub-systems that interact with each other; the integration of two sub-systems offers a first and simple alternative to address the complexity of urban systems. We suggest the use of two parametric approaches, logistic regression and house price, to model land and property sub-systems, respectively. Finally, we stress that further studies are needed to integrate the inverse model with other statistical techniques that also deal with complexity, such as cellular automata (CA) or agent-based models.
\end{abstract}

Email: ricardo.crespo@usach.cl

Initial submission: 14.10.2020; Revised submission: 01.07.2021; Final acceptance: 09.12.2021 


\section{Introduction}

Most scholars seem to agree that the urbanisation rate is growing very rapidly worldwide. According to the United Nations (2019), today, 55\% of the world's population lives in urban areas, a proportion that is expected to increase to $68 \%$ by 2050. Although urbanisation is a natural process with positive effects on society, it is also well known that high rural-urban migration rates may produce undesired effects such as urban sprawls, unemployment, pollution and increased crime rates, amongst other problems (Ahmed and Islam 2014, Zhang 2016, Bhat et al. 2017). Looking at these facts, several practical questions arise when it comes to devising future sustainable cities. For instance, will cities in the future be prepared to absorb massive rural-urban migration in a sustainable way? What are governments doing today to address the approaching changes in urban and rural societies? Are the governments working towards the right direction? United Nations (2019) warn that the preparation for this growth all depends on the decisions made now. Hence, it becomes essential to assist governments with appropriate policies and actions to be taken today in the attempt to secure sustainable future cities.

To deal with these undesired uncertainties in the planning process, policymakers and researchers often turn to statistical methods and models to forecast future urban patterns. One popular technique is cellular automata (CA), a rule-based method capable of simulating future states of urban patterns represented by a grid cell arrangement over space. Moreover, the rules determine whether a cell is to be urbanised or not in the future. To this end, the rules must be defined in relation to the drivers that promote urbanisation, such as urban regulations, population movement, population growth, land price, planned actions and geographical conditions, to mention just a few. Various scholars have stressed the importance of CA in urban modelling. One of them, Batty (2005) argued in favour of understanding cities by the means of complexity science techniques, such as CA, agent-based models and fractals. Other scholars, including Liu and Phinn (2003), Fuglsang et al. (2013) and Gonçalves et al. (2019), conducted more applied studies where CA is used to forecast city growth in Sidney, Copenhagen and Cape Verde, respectively.

Other remarkable methodological contributions to urban planning come from econometrics and spatial econometrics. For example, logistic regression is a popular method for modelling rural-urban land use change (Allen and $\mathrm{Lu} 2003, \mathrm{Hu}$ and $\mathrm{Lo}$ 2007, Khajeh Borj Sefidi and Ghalehnoee 2016, Gangopadhyay et al. 2020, Kantakumar et al. 2020). The method seeks the probability of land use change in terms of a set of explanatory variables associated with urbanisation drivers, such as climate, population density or accessibility, to mention a few. To deal with a potential spatial autocorrelation in the data, some scholars have proposed the spatial autologistic regression model (SALR). Similar to the spatial autoregressive model (SAR) introduced 
by Anselin (1988), SALR incorporates a spatially lagged term to account for the probability of the neighbouring cells of the grid. Although Dormann (2007) has questioned the statistical validity of SALR, the model has been used in land use change studies by Millington et al. (2007), Tayyebi et al. (2010), Wu et al. (2010) and Jiang et al. (2015).

Some scholars have improved the accuracy of future urban pattern predictions by integrating several of these methods. This is the case of Siddiqui et al. (2018) and Wang et al. (2019) who combined logistic regression, CA and a Markov model to simulate future urban patterns. Both studies conclude that the integration facilitates the simulation process and increases the accuracy of the results compared with logistic regression alone. Nevertheless, the authors highlight the need to include socioeconomic driving forces to further enhance accuracy. Another interesting study was conducted by Kantakumar et al. (2019), who combined remote sensing data with scenario-based analysis to improve the role of urban planning on studying rapid urbanisation in Indian cities. The authors developed a scenario-based urban growth simulation model (SUSM) that uses logistic regression model and stochastic constrained CA for the spatial simulation of urban growth. In terms of modelling, SUSM treats cities as complex adaptive systems and therefore attempts to cope with the inherent dynamics and complex non-linear behaviour present in urban systems. Another integrative approach of urban modelling and scenario-based analysis was conducted by Dorning et al. (2015). The authors integrate a modified and more suitable CA method for urban growth, land suitability mapping and landscape pattern analysis to explore urban sustainability under different growth circumstances.

Despite most of these models and methods having been very important in promoting the awareness of urban processes, they approach the problem mostly from a today perspective. In other words, they use current data to forecast the future states of cities. In this regards, Grêt-Regamey and Crespo (2011) claim that this can lead to a dead end if the drivers of current problems become the main drivers of the planning process, thus transferring our problems to the future. To deal with this inconvenience, the same authors have proposed a novel approach, denoted as planning from a future vision: an inverse model in spatial planning.

As opposed to traditional planning processes, the point of departure of this novel approach is a desired future defined by the stakeholders. From this point on, a topdown quantitative analysis is performed, giving rise to actions to be taken by planners today to achieve such a desired future. As the forward model, Grêt-Regamey and Crespo (2011) regressed house prices on a linear combination of house price drivers. Next, the model is inverted to find an economic compensation scheme for the residents affected by noise emitted from nearby highways and the airport. The set of possible solutions is given by a linear combination of values for house drivers so that economic 
compensation is achieved. However, the indicated cities are considered complex urban systems made up of highly heterogeneous sub-systems connected by complex interactions (Batty 2009, Baynes 2009). As documented by Liu (2009), the examples of urban sub-systems that interact with each other are population, land, employment, transport, property and infrastructure, to mention a few. The linear hedonic house price model used by Grêt-Regamey and Crespo (2011) concentrates on the analysis of one single sub-system: property. It thereby ignores any interaction between the property sub-system under study and the rest of the urban sub-systems. This may steer the whole urban system into an undesired future state since all sub-systems are far from remaining unchanged over time. Thus, along with being analogous to the butterfly effect example widely illustrated in the study of complex systems (Lorenz 1963), a wrong planning decision today may cause severe conflicts in the urban development in the future.

Accordingly, we think that the whole planning process should combine a systemoriented forward model to be inverted with a participative definition of the future city defined by the stakeholders. Clearly, cities can be described and defined following a myriad of concepts, approaches, or viewpoints. For instance, OrtegonSanchez and Tyler (2016) conceptualise a desirable future city state in terms of a set of five fundamental urban principles: active and inclusive city, courteous city, city as a public space, evolving and healthy city. The authors argue that these principles are the initial message to start a dialogue between the people and the city's agents to engage, commit and promote transformative actions. From an architecture perspective, Schmitt (2013) focuses on the role of spatial dimension and geometry to characterise cities. Following a more systemic approach, cities can be characterised by a set of measurable indicators that describe each of the abovementioned interacting components defined by Liu (2009).

This paper aims to suggest the use of the inverse modelling approach to support urban planners and stakeholders to deal with urban complexities in the planning process based on literature review. To this end, we follow Liu (2009)'s vision of a city and focus our attention on describing cities according to two sub-systems that interact with each other: land and property. We suggest a set of measurable indicators that describe both systems and that are associated with: land use; land use change; climate; geography; public transport network; urbanisation of commercial, industrial and residential zones; types of dwellings preferred by the residents; and amenities, amongst others.

We recommend the use of a logistic land use change modelling to understand urban growth dynamics for the former sub-system, whilst we recommend hedonic house price modelling to capture the residents' preferences for the latter. Arguably, land use change modelling provides information on where cities will grow, whilst the hedonic modelling provides information on what type of properties the residents prefer. 


\section{Methodology}

The inverse problem can be briefly defined as a mathematical procedure by which a set of model parameters characterising a physical system is derived from observed data (output of the physical system). This is particularly useful in cases when the inherent complexity of some physical systems makes it difficult for scientists to grasp the dynamics governing the system under study merely from the theory. As its name suggests, the inverse problem operates oppositely to the forward problem. The latter produces new data based on a set of given or previously estimated parameters characterising the system. Both mathematical approaches are represented in Figure 1 , following the sketch provided by Scales and Snieder (2000), where G is a linear or nonlinear mathematical operator linking the model's parameters $(\mathrm{m})$ with a vector of data (d). Thus, prior knowledge of the mathematical operator $\mathrm{G}$ becomes fundamental to solve both the forward and inverse problems.

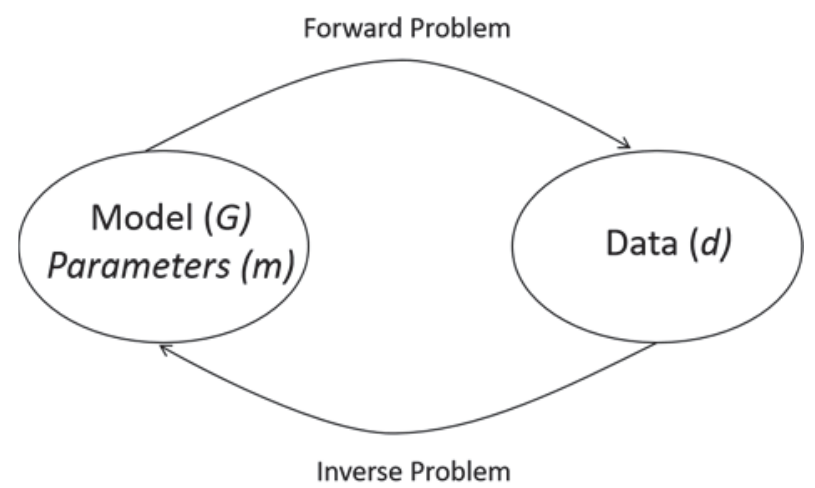

Figure 1. Representation of the forward and inverse problems. Source: Scales and Snieder (200o)

Further, based on Aster et al. (2013), a mathematical formulation of the inverse problem is represented as follows:

$$
d=\mathrm{G}(m)
$$

The solution of the inverse model is given by the set of estimated parameters $\widehat{m}$ so that $G(\widehat{m})$ becomes close to $d$. According to Engl et al. (2000), there are two possible interpretations of the solution. First, the estimated parameters represent past states or parameters of a physical system. In other words, the solution represents the initial conditions of the system under study. Second, the solution provides guidance on how to influence a system via its present state or parameters to steer it to a different state in the future. For this reason, the solution of the inverse approach has found applications in fields such as exploration geophysics (Parker 1994, Scales and Tenorio 2001, Tarduno et al. 2009, Menke 2018), environmental modelling (Kaminski and Heimann 2001, 
Giudici 2002, Henze et al. 2009), medical imaging (Louis 1997, Arridge 1999) and engineering applications (Soemarwoto et al. 2000, Martinez-Luaces 2009, Schneider et al. 2009).

However, in many cases, the solution of the inverse problem may not be unique. More than one set of estimated parameters $\hat{m}$ solve Equation 1 . This is referred to in the literature as the ill-posed problem (Tarantola 2005, Aster et al. 2013). In addition, the ill-posed problem is associated with solutions that are mathematically unstable. The inconvenience of unstable solutions is that small changes in observations may correspond to big changes in the phenomenon under study (Rabino and Laghi 2002). Non-uniqueness and/or unstable solutions make the inverse problem difficult to solve; thereby, sophisticated mathematical methods are often necessary to cope with the illposed problem. Louis (1996) provides a comprehensive review of various mathematical algorithms and approaches to deal with the problem. Additionally, Rabino and Laghi (2002) suggest the use of prior information to delimit the space of solution and to contribute to reducing the instability of solutions.

\section{Results}

\section{The inverse approach in spatial planning}

The ability of the inverse modelling approach to support urban planning has been examined in three recent studies. In the first, Grêt-Regamey and Crespo (2011) use the results from an inverse model analysis to quantify how much a public or private investor might have to compensate the residents for future planned noise-emitting factories in a metropolitan area in Switzerland. To this end, the authors use a hedonic house price model to quantify the negative relationship between the high level of noise and property values. To find the desired economic compensation scheme, a trade-off analysis between key house pricing drivers was performed. Typical house pricing drivers are selected from locational, structural, and environmental house price determinants. In other words, the trade-off analysis offers planners a wide set of possible combinations between the selected key drivers from which the residents are to be economically compensated because of a higher level of noise in the proximity.

The trade-off analysis plays a fundamental role in the use of the inverse model in urban planning because it tackles the problem of unfeasible solutions due to economic restrictions or conflicts between public and private parties. It is worth noting that the ill-posed problem is not actually a problem in urban planning; rather, it is a favourable condition for the trade-off analysis. In the second study, Crespo and Grêt-Regamey (2012) provide the theoretical framework for the inverse model in spatial planning and present a new case study to illustrate how to cope with the increasing population density in the metropolitan area of Zurich by the housing market. Additionally, Crespo 
et al. (2016) suggest the use of an inverse model coupled with a land use change model to examine urbanisation in a city in southern Chile.

\section{The inverse model for planning future cities}

As its name suggests, future city planning is concerned with making strategic decisions today to ensure sustainability and well-being in cities in the future. As discussed above, the proposed inverse model becomes a sound top-down mathematical technique to support planners in the decision-making process. However, in the field of urban planning, strategic decisions involving the future of cities should rely not only on the output of mathematical models but also on the knowledge of relevant experts in the matter. In the context of the inverse model, the knowledge of experts can be used to reduce the space of possible solutions by leaving out political, practical, and economic unfeasible solutions. In this regard, Scales and Snieder (2000) state that, in practical inverse models, decisions are usually not based exclusively on the estimated model but involve the integration of other data and human expertise. Based on a figure provided in the above-mentioned work of Scales and Snieder (2000), we extend Figure 1 and present a new figure (Figure 2) that sketches the framework of the inverse model for planning future cities that we propose in this study.

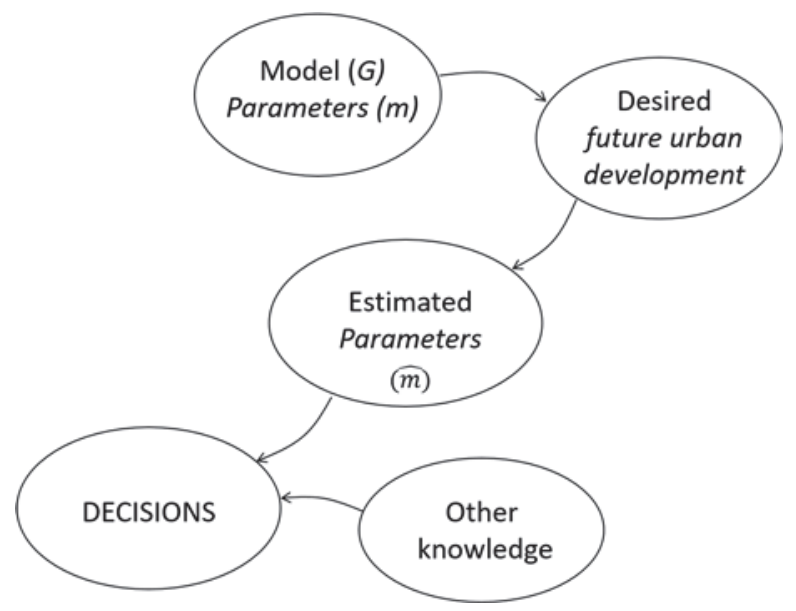

Figure 2. Representation of the forward and inverse models for planning future cities. Source: own elaboration and Scales and Snieder (2000)

In this case, the set of the model's parameters denoted by $m$ represents a group of key drivers of urban processes over time. Typical examples of urban processes are urban growth (often measured by the rate of rural-urban land use conversion) and residential-commercial or residential-industrial land use conversion. Likewise, examples for the drivers of urban processes are agriculture subsidies, migration rate, industrialisation, and increased population density. Consequently, the selection of the 
proper mathematical model $(G)$ for the urban process under study becomes of great importance in planning future cities and therefore the identification of the key drivers $(m)$ that control the process. As indicated in the introduction, typical mathematical models used in urban planning are CA, hedonic house price models, logistic regression, and the Markov processes, amongst others.

It should be noted that the definition of the desired future urban development becomes the most important step in the planning process. Defining a future planning scenario involves the participation of various stakeholders: residents, public and private institutions, and local and regional authorities, amongst others. It is expected that the actors of the process may have a completely different understanding at the moment of defining a future urban development in a given geographical area. It is therefore crucial for the sake of the planning process that all participants not only to agree with a future urban development but also to have a close understanding of the shape, attributes, and design of the future urban development scenario. In other words, all actors of the planning process must speak the same language when devising a future urban development.

The concept of urban development is highly dependent on the level of aggregation of the analysis. If the analysis is performed at a district or municipality level, the concept of urban development may be more closely associated to the urban design of small areas, whilst the concept of urban development is more likely to be associated to infrastructure and the demographic or socio-economic characteristics of the city or region if the analysis is performed at a city or regional level. It is also worth pointing out that both the forward and inverse models deal with mathematical modelling; therefore, the concept of urban development should be quantifiable by a set of indicators such as city size, dwelling type, population density, public transport network, central business district location, and commercial, industrial, or residential zones, amongst others.

Once the urban process to be studied and its drivers, and the desired future urban development defined by the stakeholders are selected, the next step is to solve the inverse model for the key parameters (drivers). This set of estimated parameters $(\widehat{m})$ are then used as guidelines over time to make key decisions today to achieve the desired future urban development. The item 'other knowledge' summarises the expert opinion and human expertise supporting a final decision in the planning process. They become fundamental to reduce the space of solutions by leaving out the impracticable solutions that may be technically infeasible or not recommended politically. The whole planning process is finally completed with the decisions to be made today to achieve the desired future. The decisions are derived from the solutions of the inverse model and they should clearly provide stakeholders with the guidelines to gradually achieve the desired future. 


\section{A general framework of the integration of the inverse model to land and property sub-systems}

Next, it becomes necessary to define a general framework for a participatory urban planning approach. To this end, we propose an integrated land and property system model to deal with urban complexities. The drivers of the land system may be also the drivers of the property system. In fact, understanding land use changes over time is, in some ways, similar to understanding how urbanisation evolves. Both processes are clearly interconnected, as rapid urban population growth occurs as a result of increasing demand for urban lands, particularly for housing (Thuo 2013).

We propose the integrated framework depicted in Figure 3. As it can be observed, the main actors are the stakeholders, modellers, and planners. Whilst stakeholders deal with the definition of the desired future urban development, modellers deal with system identification. As pointed out by Tarantola (2005), the latter task includes the parameterisation of the system for both forward and inverse modelling approaches. The output of the modeller's stage corresponds to a set of recommended actions to be taken by planners; thus, the appropriate system identification becomes crucial to solve the inverse problem and thus to provide reliable recommendations.

Therefore, it is now necessary to define the type of model $G$ from which the key parameters are to be derived to perform the inverse analysis. In this study, we suggest the use of a logistic land use change and hedonic house price models to deal with land and property systems.

Land use change models have been of great importance in forecasting future land patterns and therefore finding out where a next urbanisation process is more likely to occur. The dynamics of land use change comes as a result of the complex interactions between the human and the physical environment (Verburg et al. 2004). To deal with these complexities, various statistical approaches have been proposed as documented by Koomen and Stillwell (2007). One of these statistical approaches most often found in the literature is the logistic regression approach, by which the observed land use change (usually at parcel level) between two or more time periods is regressed on a set of drivers associated to terrain, climate, accessibility, economic and socio-economic attributes, amongst others. Typical drivers associated to terrain attributes are slope and soil degradation. In addition, the typical drivers associated to climate are sunshine exposure, average temperature, and rainfall. In the case of accessibility, variables such as the distance to roads and highways or the proximity to bus or train stations are frequently used. Finally, variables associated to agricultural subsidies, tax levels or land ownership conflicts are often selected as economic and socio-economic drivers. Logistic regressions deal with probabilities, which in this case corresponds to the probability that a given land use change (e.g. in the case of rural-urban) occurs during two time periods. Such probabilities are strongly correlated to the parameter estimates 
obtained from the regression and associated to each variable (driver). The order of magnitude of the parameter estimates and their statistical significance provide planners with useful and relevant information to identify the drivers that are more strongly (positively or negatively) correlated with the urbanisation process analysis.

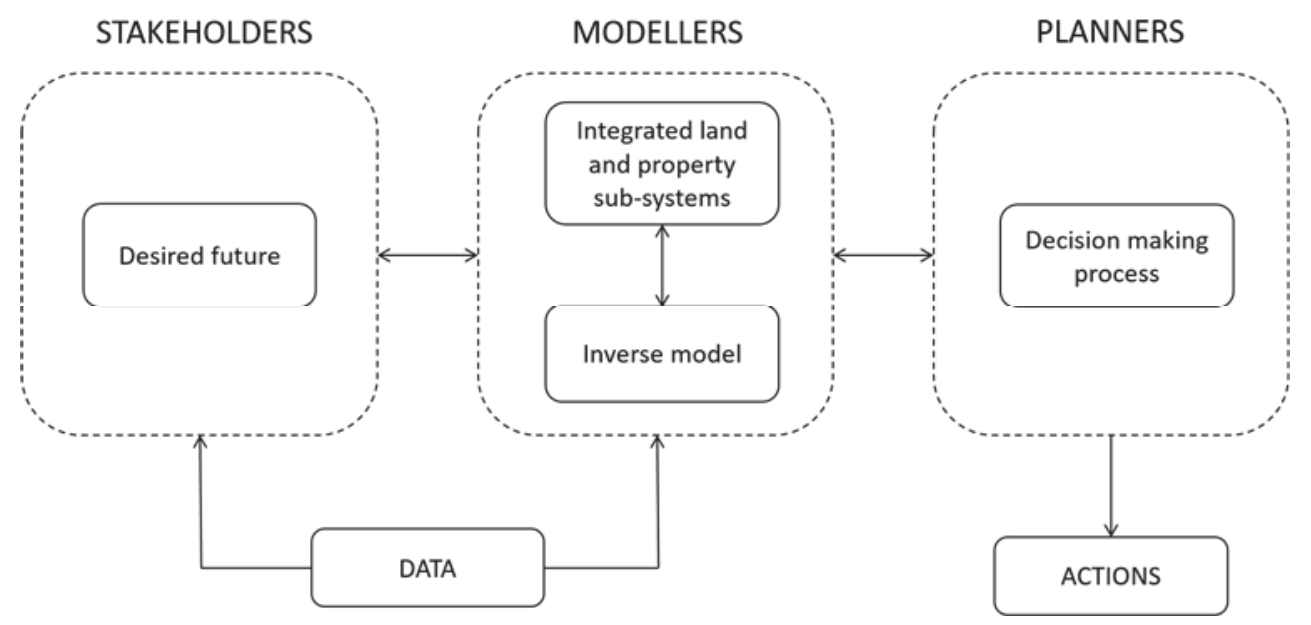

Figure 3. Framework of the integrated land and property sub-systems

Similarly, the urbanisation trends may also be explored by studying the housing market. As with the land use analysis, urbanisation and the housing market are closely related. Very often, urbanisation causes the demand for dwellings to increase more rapidly than the supply. Therefore, house prices tend to exhibit an upward trend overtime. In addition to any temporal trend, house prices frequently exhibit spatial variability, mostly caused by the heterogeneous residents' preferences for dwelling attributes (Fotheringham et al. 2002, Bitter et al. 2007, Helbich et al. 2014). It is reasonable to expect that the residents' preferences for house attributes vary not only over space but also over time. This is because cities, as complex adaptive systems, are constantly evolving and adapting themselves to external shocks. For instance, a demand shock for housing is likely to have, at least in the short term, a negative impact on the urban attributes such as mobility, accessibility to workplace, crime rate, unemployment rate and pollution levels, amongst others. It is also expected that households tend to compensate this loss of well-being by moving out to neighbourhoods with better accessibility or dwellings with higher standards.

One of the most popular statistical techniques to explore the relationship between the house prices and the households' preferences is the hedonic house price modelling. This technique is intended to model the price of properties in terms of quantitative and measurable attributes related to those properties. Typical attributes included in the model are associated to the structural, locational and neighbourhood characteristics of properties. Structural attributes refer to the physical characteristics of properties, such 
as number of rooms and bedrooms, number of bathrooms, floor area, building age and the existence of basement, garage, balcony, and heating system, amongst others. In turn, locational attributes refer mostly to accessibility to central business districts and proximity to schools, shopping centres, bus stops, railway, train stations, airports and amenities, amongst others (Chin and Chau 2003). Finally, the neighbourhood attributes refer to the socio-economic characteristics of the surrounding neighbourhood, such as the social class of the area, the unemployment rate, the crime rate, the racial diversity, and the occupations of the inhabitants. Hedonic house price models are frequently fitted by ordinary least square or spatial autoregressive regression to account for spatial autocorrelation. The outcomes from a logistic land use change model provide useful insights on where city expansions are more likely to occur; and which drivers are more strongly associated to such expansion. Likewise, the outcomes from the hedonic house price model provide useful information on the resident's preferences in a spatially explicit manner and contribute to answering the question: what type of property or neighbourhood will the future residents prefer?

Clearly, the dynamics of land and property systems should not be studied separately from one another. Both systems have common drivers associated to locational, socioeconomic and environmental or infrastructure attributes, i.e. accessibility to road networks, level of population density around, proximity to amenities and infrastructure development. For this reason, the use of these drivers in urban planning should be done with care as it may steer systems to undesired future states. For example, improved accessibility is likely to foster rural-urban land use change as most people, mostly commuters, tend to live near road networks. However, it is not always clear whether the values of the surrounding existing properties will drop or rise because of better accessibility as some may prefer to reside in more remote and quiet places. Similarly, promoting industrial zones will likely foster rural-urban land use change because of new employment alternatives; however, house values are likely to drop as the residents tend to associate industrial zones with air and noise pollution, as well as with disturbing freight traffic coming in and out. Thus, when studying land and property systems for spatial planning, we can generally distinguish two types of drivers: system-specific drivers, i.e. those that only affect the output of each system, and common drivers, i.e. drivers that simultaneously trigger changes in both systems.

Identifying both types of drivers and understanding the extent to which they influence the output of systems shed important light on performing trade-off analysis in spatial planning. By doing so, the undesired effects on a system caused by the new values for drivers of the other system can be compensated by finding an appropriated set of values from the system-specific drivers. Again, because of the complexity of modelling both systems together, the inverse model analysis at this point should be done with caution. It may happen that some combinations of either system-specific or common drivers from both systems lead the whole process to a desired future state; however, it 
may also happen that a certain combination of drivers from both systems leads the whole process to an absolute undesired future urban development. When dealing with public policy, the latter case may imply an important and irreversible waste of time and money. One easy example to illustrate how a public policy may produce undesired effects on a system corresponds to the construction of highways near rural areas. According to land use change modelling, highways across rural areas are likely to foster urbanisation, i.e. to induce rural-urban land use conversion. Commuters benefit from the construction of highways nearby; however, highways are also associated to high traffic, noise, and vehicular congestion. Some residents may demand compensation for this loss in their quality of life, such as improved amenities or public transport infrastructure.

\section{Discussion}

As stated above, urban systems are made of various sub-systems with very complex interactions. In this study, with the purpose of facilitating the introduction of the proposed integrated inverse approach, particularly the trade-off analysis, we selected only two of these sub-systems: land and property systems. Thus, future research should concentrate on integrating other urban sub-systems. We suggest the transport system because of its evident influence on city development. Clearly, an efficient transport system yields superior labour mobility, industrial and commercial development, land and property values and tourism activities, amongst others. Transport systems play a fundamental role in shaping future cities and promoting urbanisation. However, it should also be noted that the more city sub-systems are included in the analysis, the higher the complexity of the mathematical modelling necessary to solve the inverse model. In this sense, further research should also address the complexity of urban systems in space and time more thoroughly. In complex systems, most relationships between explanatory and exploratory variables may exhibit non-linearities; urban systems are not the exception to the rule.

In relation to the methods used to model land and property systems, we selected two parametric approaches: logistic regression and hedonic house price. In both cases, independent variables are associated with a linear parameter that represents the extent to which changes in the variables affect the response variable. The advantage of these methods over nonparametric approaches, such as CA, is that the information contained in the parameter estimates can be passed onto planners in a more straightforward manner. Planners can identify more easily the measures (each of them associated with an independent variable) that are more influential, feasible and urgent for carrying out actions.

In addition, the results can be displayed in a spatially explicit manner using local spatial techniques such as geographically weighted regression (GWR). This technique, 
developed by Fotheringham et al. (2002), allows estimates to vary across space estimating as many parameters estimates as the number of points in the sample. As done by Grêt-Regamey and Crespo (2011) and Crespo and Grêt-Regamey (2012), local estimates can be clustered over space to define different planning actions at small area levels. The applications of GWR in land use change and hedonic house price models can be found in Helbich et al. (2014) and Zhao et al. (2020), respectively. Although CA is not a parametric technique, very close attention should be placed on the recent work conducted by Feng and Tong (2018), who integrated GWR and CA to produce nonstationary rules over space. With the parametric approach, the inverse model is solved for the independent variables; therefore, a trade-off analysis between key house pricing and land use drivers is possible. In the case of the integrated GWR-CA, this trade-off analysis is not straightforward. We think that further work remains needed to integrate this approach with the inverse model. This integration can be a promising step forward as techniques such as CA or agent-based models are probably more robust to deal with urban complexity.

\section{Conclusions}

To bring the proposed methodology into actions, there remain some other challenges to deal with, e.g. the conversion of abstract concepts in urban planning into quantitative data to fit the models. A desired future defined by stakeholders cannot always be derived from quantifiable concepts such as the percentage of land use conversion, desired rate of urbanisation or type and size of property. Frequently, stakeholders tend to discuss general concepts on the types of future urban development scenarios, such as business-as-usual land use, mostly tourism landscape or business-oriented city development. Obviously, several urban structures may be associated to each one of these types of urban development, making the definition of the desired future a complex decision. To deal with this inconvenience, we suggest future studies to integrate $3 \mathrm{D}$ visualisation techniques as a way to visualise the output of mathematical models.

Another relevant challenge in urban planning is concerned with the sustainability of cities. Experts worldwide seem to agree that the rapid urbanisation rate is becoming a serious threat to urban sustainability. Rapid urban growth at the expense of future food or ecosystem service provision is not precisely a desired future. Thus, the achievement of a not only desired but also sustainable future urban development is another interesting application of the inverse model approach. To this end, for further research, we propose the elaboration of a general function accounting for the welfare of society in a way that the solution of the inverse model provides the actions to be made today to achieve the desired future development in a sustainable manner. Broadly speaking, such a well-being function should include social, environmental 
and economic variables to secure in the long-term food, ecosystem service and energy provision, as well as an environment free of pollution.

In summary, despite the above-mentioned challenges, we think that this study addresses an interesting way to move ahead to extend the novel work of GrêtRegamey and Crespo (2011) and Crespo and Grêt-Regamey (2012), who proposed the use of the inverse model in urban planning. The process of forecasting possesses an intrinsic risk of missing the target, even when using complex mathematical modelling. Therefore, it becomes important to first define a desired future defined by the stakeholders and an appropriate model or combination of models to deal with urban complexity. By doing so, the risk of missing the target may be reduced significantly. A solution with zero risk is not possible because of the inherent uncertainty of statistical models and data. Finally, it is worth mentioning that we also expect this methodology to be fully integrated on a friendly user web-based platform available for planners from either the industry or the public sectors at different geographical levels, such as municipality, city, or regional levels. It is also important to bring more abstract mathematical concepts to real application for users not familiar with such concepts.

\section{References}

AHMED M. F., ISLAM M. S. (2014) Urbanization and Environmental Problem: An Empirical Study in Sylhet City, Bangladesh, Research on Humanities and Social Sciences 4 (3), 161-172.

ALLEN J., LU K. (2003) Modeling and Prediction of Future Urban Growth in the Charleston Region of South Carolina: a GIS-based Integrated Approach, Conservation Ecology 8 (2), 2.

ANSELIN L. (1988) Spatial Econometrics: Methods and Models, Kluwer Academics, Dordrecht.

ARRIDGE S. R. (1999) Optical tomography in medical imaging, Inverse Problems 15 (2), R41.

ASTER R. C., BORCHERS B., THURBER C. H. (2013) Parameter Estimation and Inverse Problems, Elsevier, New York.

BATTY M. (2005) Cities and Complexity: Understanding Cities with Cellular Automata, Agent-Based Models, and Fractals, The MIT Press, Cambridge, MA.

BATTY M. (2009) Cities as Complex Systems: Scaling, Interaction, Networks, Dynamics and Urban Morphologies, in: Meyers R. A. (ed.) Encyclopedia of Complexity and Systems Science, Springer, New York, pp. 1041-1071.

BAYNES T. M. (2009) Complexity in Urban Development and Management: Historical Overview and Opportunities, Journal of Industrial Ecology 13 (2), 214-227. 
BHAT P. A., UL SHAFIQ M., MIR A. A., AHMED P. (2017) Urban sprawl and its impact on landuse/land cover dynamics of Dehradun City, India, International Journal of Sustainable Built Environment 6 (2), 513-521.

BITTER C., MULLIGAN G. F., DALL'ERBA S. (2007) Incorporating spatial variation in housing attribute prices: A comparison of geographically weighted regression and the spatial expansion method, Journal of Geographical Systems 9, 7-27.

CHIN T. L., CHAU K. W. (2003) A critical review of literature on the hedonic pricing model and its application to the housing market in Penang, International Journal for Housing Science and Its Applications 27 (2), 145-165.

CRESPO R., GRÊT-REGAMEY A. (2012) Spatially explicit inverse modeling for urban planning, Applied Geography 34, 47-56.

CRESPO R., MANUSCHEVICH D., CRESPO F., CONCHA G., RAJABIFARD A. (2016) Participatory planning process for controlling urbanization: an inverse model approach, ICEGOV '15-16: Proceedings of the 9th International Conference on Theory and Practice of Electronic Governance, 378-379.

DORMANN C. F. (2007) Assessing the validity of autologistic regression, Ecological Modelling 207 (2-4), 234-242.

DORNING M. A., KOCH J., SHOEMAKER D. A., MEENTEMEYER R. K. (2015) Simulating urbanization scenarios reveals tradeoffs between conservation planning strategies, Landscape and Urban Planning 136, 28-39.

ENGL H. W., HANKE M., NEUBAUER A. (2000) Regularization of Inverse Problems, Kluwer Academic Publishers, Dordrecht.

FENG Y., TONG X. (2018) Dynamic land use change simulation using cellular automata with spatially nonstationary transition rules, GIScience \& Remote Sensing 55 (5), 678-698.

FOTHERINGHAM A. S., BRUNSDON C., CHARLTON M. (2002) Geographically Weighted Regression: the analysis of spatially varying relationships, Wiley, Chichester.

FUGLSANG M., MÜNIER B., HANSEN H. S. (2013) Modelling land-use effects of future urbanization using cellular automata: An Eastern Danish case, Environmental Modelling \& Software 50, 1-11.

GANGOPADHYAY P., JAIN S., SUWANDARU A. (2020) What Drives Urbanisation in Modern Cambodia? Some Counter-Intuitive Findings, Sustainability 12 (24), 10253.

GIUDICI M. (2002) Some problems for the application of inverse techniques to environmental modeling, Contemporary Mathematics 333, 89-97.

GONÇALVES T. M., ZHONG X., ZIGGAH Y. Y., DWAMENA B. Y. (2019) Simulating Urban Growth Using Cellular Automata Approach (SLEUTH)-A Case Study of Praia City, Cabo Verde, IEEE Accesss 7, 156430-156442. 
GRÊT-REGAMEY A., CRESPO R. (2011) Planning from a future vision: Inverse modeling in spatial planning, Environment and Planning B: Planning and Design 38 (6), 979-994.

HELBICH M., BRUNAUER W., VAZ E., NIJKAMP P. (2014) Spatial Heterogeneity in Hedonic House Price Models: The Case of Austria, Urban Studies 51 (2), 390-411.

HENZE D. K., SEINFELD J. H., SHINDELL D. T. (2009) Inverse modeling and mapping US air quality influences of inorganic PM2.5 precursor emissions using the adjoint of GEOS-Chem, Atmospheric Chemistry and Physics 9 (16), 5877-5903.

HU Z., LO C.P. (2007) Modeling urban growth in Atlanta using logistic regression, Computers, Environment and Urban Systems 31 (6), 667-688.

JIANG W., CHEN Z., LEI X., JIA K., WU Y. (2015) Simulating urban land use change by incorporating an autologistic regression model into a CLUE-S model, Journal of Geographical Sciences 25 (7), 836-850.

KANTAKUMAR L. N., KUMAR S., SCHNEIDER K. (2020) What Drives Urban Growth in Pune? A Logistic Regression and Relative Importance Analysis Perspective, Sustainable Cities and Society 60, 102269.

KHAJEH BORJ SEFIDI A., GHALEHNOEE M. (2016) Analysis of urban growth pattern using logistic regression modeling, spatial autocorrelation and fractal analysis. Case study: Ahvaz city, International Journal of Architectural Engineering \& Urban Planning 26 (2), 183-194.

KAMINSKI T., HEIMANN M. (2001) Inverse modeling of atmospheric carbon dioxide fluxes, Science 294 (5541), 259.

KANTAKUMAR L. N., KUMAR S., SCHNEIDER K. (2019) SUSM: a scenario-based urban growth simulation model using remote sensing data, European Journal of Remote Sensing 52 (S2), 26-41.

KOOMEN E., STILLWELL J. (2007) Modeling Land Use Change: Theories and Methods, in: Koomen E., Stillwell J., Bakema A., Scholten H. J. (eds.) Modelling land-use change: Progress and applications, Springer, Dordrecht, pp. 1-21.

LIU Y. (2009) Modelling Urban Development with Geographical Information Systems and Cellular Automata, CRC Press, Boca Raton.

LIU Y., PHINN S. R. (2003) Modeling urban development with cellular automata incorporating fuzzy-set approaches, Computers, Environment and Urban Systems 27 (6), 637-658.

LORENZ E. N. (1963) Deterministic nonperiodic flow, Journal of the Atmospheric Sciences 20 (2), 130-141.

LOUIS A. K. (1997) Application of the approximate inverse to 3D X-ray CT and ultrasound tomography, in: Engl H. W., Louis A. K., Rundell W. (eds.) Inverse Problems in Medical Imaging and Nondestructive Testing, Springer, Vienna, pp. 120-133. 
MARTINEZ-LUACES V. (2009) Modelling and inverse-modelling: experiences with O.D.E. linear systems in engineering courses, International Journal of Mathematical Education in Science and Technology 40 (2), 259-268.

MENKE W. (2018) Geophysical Data Analysis: Discrete Inverse Theory, Elsevier, London.

MILlingtON J. D. A., PERRY G. L. W., ROMERO-CALCERRADA R. (2007) Regression techniques for examining land use/cover change: A case study of a Mediterranean landscape, Ecosystems 10, 562-578.

ORTEGON-SANCHEZ A., TYLER N. (2016) Constructing a Vision for an 'Ideal' Future City: A Conceptual Model for Transformative Urban Planning, Transportation Research Procedia 13, 6-17.

PARKER R. L. (1994) Geophysical Inverse Theory, Princeton University Press, Princeton.

RABINO G. A., LAGHI A. (2002) Urban Cellular Automata: The Inverse Problem, in: Bandini S., Chopard B., Tomassini M. (eds.) Cellular Automata. ACRI 2002. Lecture Notes in Computer Science 2493, Springer, Berlin, pp. 349-356.

SCALES J., SNIEDER R. (2000) The Anatomy of inverse problems, Geophysics 65 (6), 1708-1710.

SCALES J. A., TENORIO L. (2001) Prior information and uncertainty in inverse problems, Geophysics 66 (2), 389-397.

SCHMITT G. (2013) Spatial modeling issues in future smart cities, Geo-Spatial Information Science 16 (1), 7-12.

SCHNEIDER P. S., MOSSI A. C., FRANÇA F. H. R., DE SOUSA F. L., DA SILVA NETO A. J. (2009) Application of inverse analysis to illumination design, Inverse Problems în Science and Engineering 17 (6), 737-753.

SIDDIQUI A., SIDDIQUI A., MAITHANI S., JHA A. K., KUMAR P., SRIVASTAV S. K. (2018) Urban growth dynamics of an Indian metropolitan using CA Markov and Logistic Regression, The Egyptian Journal of Remote Sensing and Space Science $21(3), 229-236$.

SOEMARWOTO B. I., LABRUJÈRE T. E., LABAN M., YANSYAH H. (2000) Inverse aerodynamic shape design for improved wing buffet-onset performance, in: Tanaka M., Dulikravich G. S. (eds.) Inverse Problems în Engineering Mechanics II, Elsevier, Nagano, pp. 419-428.

TARANTOLA A. (2005) Inverse Problem Theory and Methods for Model Parameter Estimation, Inverse Problem Theory and Methods for Model Parameter Estimation, SIAM: Society for Industrial and Applied Mathematics, Philadelphia.

TARDUNO J., BUNGE H.-P., SLEEP N., HANSEN U. (2009) The Bent HawaiianEmperor Hotspot Track: inheriting the mantle wind, Science 324 (5923), 50-53. 
TAYYEBI A., DELAVAR M. R., YAZDANPANAH M. J., PIJANOWSKI B. C., SAEEDI S., TAYYEBI A. H. (2010) A spatial logistic regression model for simulating land use patterns: A case study of the Shiraz Metropolitan Area of Iran, in: Chuvieco E., Li J., Yang X. (eds.) Advances in Earth Observation of Global Change, Springer, Dordrecht, pp. 27-42.

THUO A. D. M. (2013) Impacts of urbanization on land use planning, livelihood and environment in the Nairobi rural-urban fringe, Kenya, International Journal of Scientific \& Technology Research 2 (7), 70-79.

UNITED NATIONS (2019) World Urbanization Prospects: The 2018 Revision, United Nations, New York.

VERBURG P. H., VAN ECK J. R. R., DE NIJS T. C. M., DIJST M. J., SCHOT P. (2004) Determinants of land-use change patterns in the Netherlands, Environment and Planning B: Planning and Design 31 (1), 125-150.

WANG M., CAI L., XU H., ZHAO S. (2019) Predicting land use changes in northern China using logistic regression, cellular automata, and a Markov model, Arabian Journal of Geosciences 12, 790.

WU G., ZENG Y., XIAO P., FENG X., HU X. (2010) Using autologistic spatial models to simulate the distribution of land-use patterns in Zhangjiajie, Hunan Province, Journal of Geographical Sciences 20 (2), 310-320.

ZHANG X. Q. (2016) The trends, promises and challenges of urbanisation in the world, Habitat Internațional 54 (3), 241-252.

ZHAO C., JENSEN J. L. R., WEAVER R. (2020) Global and local modeling of land use change in the border cities of Laredo, Texas, USA and Nuevo Laredo, Tamaulipas, Mexico: A comparative analysis, Land 9 (10), 347. 